\section{Indigenous Lyme Disease in Quebec}

\section{To the Editor:}

Lyme disease is caused by the bacterium Borrelia burgdorferi, which is transmitted by ticks feeding on infected animals, mainly rodents and birds. Ixodes scapularis, also known as the blacklegged tick, is the most common vector in eastern North America ${ }^{1}$. Humans can acquire the pathogen when an infected tick feeds on them.

Lyme disease was first recognized in the late 1970s in Connecticut, USA, where an epidemic of oligoarthritis occurred ${ }^{2}$. In the following years, expanding populations of $I$. scapularis were identified in northeastern and midwestern American states ${ }^{3}$. In the early 1990s, only one population of $I$. scapularis was documented in Canada, located in Ontario ${ }^{1}$. Since then, 13 established populations of $I$. scapularis have been progressively identified in Canada ${ }^{3}$.

Recent evidence suggests that the risk of exposure to Lyme disease is increasing in the province of Quebec ${ }^{1,3,4}$. Studies indicate that $I$. scapularis is establishing itself in southern regions, near the US border ${ }^{1,3}$. Factors potentially contributing to the northward spread of I. scapularis include migratory birds and climate change ${ }^{5}$.

In 2010, Ogden, et al published data from passive and active surveillance performed in Quebec. Since 1990, a passive surveillance system collects I. scapularis through voluntarily participating veterinary and medical clinics $^{6}$. The annual number of ticks submitted through this system has increased exponentially, from $<200$ ticks in 2000 , to $>1600$ in 2008. The majority come from southern regions close to the US border.

Active surveillance performed at 71 woodland sites dispersed over 3 southern regions (Montérégie, Montréal, and Estrie) showed presence of $I$. scapularis at $55 \%$ of these sites ${ }^{3}$. The overall prevalence of B. burgdorferi in adult ticks was $13.0 \%$. Although this prevalence was lower than that generally observed in the northeastern US, where it is $\sim 25 \%$, a significant proportion of B. burgdorferi from Quebec bore genetic markers associated with severe Lyme disease ${ }^{3,7}$. However, to date, a single case of Lyme disease acquired in Quebec, at $1.5 \mathrm{~km}$ from the border with Maine, USA, had been reported in the literature, 20 years ago ${ }^{8}$.

In March 2010, we observed for the first time at our institution a case of Lyme disease contracted in Quebec. The patient, a 45-year-old military man, was referred to our rheumatology clinic to confirm the diagnosis of Lyme disease. In June 2009, he trained for several days in the woods of Farnham, a municipality located in Montérégie. Two weeks after training, he developed an expanding thoracic rash suggestive of erythema migrans. Although he did not remember having been bitten by a tick and did not travel outside Quebec for many years, Lyme disease was suspected by his family physician, and doxycycline was prescribed for 21 days, with complete resolution of the rash. B. burdorgferi serologies, performed by ELISA, were positive for $\operatorname{IgM}$ and negative for $\operatorname{IgG}$, and were confirmed by Western blot.

In September 2009, the patient developed synovitis, mainly involving his right hand. Rheumatoid factor, anti-cyclic citrullinated peptide antibodies, and antinuclear antibodies were negative. A second course of doxycycline was given for 28 days, but no improvement was noted. The patient then came to our attention and was treated with intravenous ceftriaxone for 21 days. Although his arthritis did not improve, repeated serologies showed negative $\mathrm{IgM}$ and positive $\mathrm{IgG}$ to $B$. burdorgferi, further confirming the diagnosis.

Since November 2003, reporting of Lyme disease has been mandatory in Quebec and is done through confidential case report by physicians and/or laboratories to the Direction de santé publique (DSP) of each region, with serological confirmation by the Institut national de santé publique du Québec (INSPQ). To determine if other indigenous cases had occurred, reports to the DSP were reviewed and the INSPQ was contacted. Since 2003, 8 cases of confirmed indigenous Lyme disease (including ours) have been identified out of 50 reported cases. Seven cases were acquired in Montérégie and 1 in Mauricie-Centre-du-Québec. Of these, 4 adults contracted the disease in 2008; 2 adults and 2 children in 2009. Seven patients presented with erythema migrans and 2 developed facial palsy. Prior to 2008, no indigenous case had been reported. Of note, all adult cases in Montérégie were military personnel who had trained in the woods near Farnham. Both children were probably exposed to ticks while playing in nearby woods. Only one case had a clear history of tick bite.

Data from passive and active surveillance suggest an emerging risk of exposure to Lyme disease in Quebec. Genetic analysis of B. burgdorferi indicates recent introduction from northeastern $\mathrm{US}^{3}$. In the last 2 years, at least 8 individuals developed indigenous Lyme disease. Although the overall risk of contracting the disease is currently low, projected increases in temperature are expected to accelerate the expansion of I. scapularis, potentially increasing disease risk $^{5}$. These data emphasize the need to enhance surveillance activities and to raise our suspicion index for Lyme disease in Quebec.

JOSIANE BOURRÉ-TESSIER, MD, FRCPC, Division of Rheumatology, Department of Medicine, Montreal General Hospital, McGill University Health Center, Montréal; FRANÇOIS MILORD, MD, MSc, FRCPC, Direction de santé publique de la Montérégie, Longueuil; CHRISTIAN PINEAU, MD, FRCPC; EVELYNE VINET, MD, FRCPC, Division of Rheumatology, Department of Medicine, Montreal General Hospital, McGill University Health Center, Montréal, Québec, Canada. Address correspondence to Dr. J. Bourré-Tessier, Division of Rheumatology, McGill University Health Center, 1650 Cedar Avenue, Montreal, Quebec H3G 1A4.E-mail: josiane.bourre.tessier@umontreal.ca

\section{REFERENCES}

1. Ogden NH, Lindsay LR, Morshed M, Sockett PN, Artsob H. The emergence of Lyme disease in Canada. CMAJ 2009;180:1221-4.

2. Steere AC, Malawista SE, Snydman DR, Shope RE, Andiman WA, Ross MR, et al. Lyme arthritis: an epidemic of oligoarticular arthritis in children and adults in three Connecticut communities. Arthritis Rheum 1977;20:7-17.

3. Ogden NH, Bouchard C, Kurtenbach K, Margos G, Lindsay LR, Trudel L, et al. Active and passive surveillance, and phylogenetic analysis of Borrelia burgdorferi elucidate the process of Lyme disease risk emergence in Canada. Environ Health Perspect 2010;118:909-14.

4. Trudel L, Milord F. Les tiques s'installent au Québec! Qu'en est-il de la maladie de Lyme? Antennae 2010;17:3-7.

5. Ogden NH, Bigras-Poulin M, Hanincová K, Maarouf A, O'Callaghan CJ, Kurtenbach K. Projected effects of climate change on tick phenology and fitness of pathogens transmitted by the North American tick Ixodes scapularis. J Theor Biol 2008;254:621-32.

6. Ogden NH, Trudel L, Artsob H, Barker IK, Beauchamp G, Charron $\mathrm{DF}$, et al. Ixodes scapularis ticks collected by passive surveillance in Canada: analysis of geographic distribution and infection with Lyme borreliosis agent Borrelia burgdorferi. J Med Entomol 2006;43:600-9.

7. Jones KL, Glickstein LJ, Damle N, Sikand VK, McHugh G, Steere AC. Borrelia burgdorferi genetic markers and disseminated disease in patients with early Lyme disease. J Clin Microbiol 2006;44:4407-13.

8. Vallière L, Beaudry JM, Morin D. Lyme disease: first indigenous case in Quebec. Can Dis Wkly Rep 1990;16:35-8.

J Rheumatol 2011;38:1; doi:10.3899/jrheum100768 